\title{
Temperature effect on nervous necrosis virus infection in grouper cell line and in grouper larvae
}

\author{
Shau-Chi Chi ${ }^{\mathrm{a}, *}$, Su-Ching Lin ${ }^{\text {a }}$, Huei-Meei Su ${ }^{\text {b }}$, Wei-Wen $\mathrm{Hu}^{\text {a }}$ \\ a Department of Zoology, National Taiwan University, Taipei, Taiwan, ROC \\ b Tungkang Marine Laboratory, Taiwan Fisheries Research Institute, Tungkang, Pingtung, Taiwan, ROC
}

\begin{abstract}
This preliminary study elucidates the in vitro and in vivo effects of temperature on grouper nervous necrosis virus (GNNV) infection. A novel continuous cell line derived from the fin tissue of a grouper (Epinephelus coioides, Hamilton), named as GF-1 cell line, was used. Cytopathic effect was observed in GNNV-infected GF-1 cells incubated at $24-32^{\circ} \mathrm{C}$ after viral adsorption, but not at $20^{\circ} \mathrm{C}$ or $37^{\circ} \mathrm{C}$ even though the viral adsorption temperature was $28^{\circ} \mathrm{C}$. Viral protein could be detected in the pellets of GNNV-infected GF-1 cells cultured at $20-32^{\circ} \mathrm{C}$, but not at $37^{\circ} \mathrm{C}$. In a challenge test, GNNV-challenged larvae which were maintained at a constant $28^{\circ} \mathrm{C}$ began to die 1 day post challenge (p.c.) with a death rate of $80 \%$. Mortality reached $100 \%$ by 50 h p.c., while the mortality of negative control fish was only $5 \%$. The cumulative mortality of GNNV-challenged larvae at ambient temperature, i.e. $28^{\circ} \mathrm{C}$ at noon and $24^{\circ} \mathrm{C}$ at midnight, was $10 \% 1$ day p.c., and increased to $100 \%$ by $80 \mathrm{~h}$ p.c. Based on the results, we concluded that temperature plays an important role in GNNV infection and pathogenicity. (C) 1999 Elsevier Science B.V. All rights reserved.
\end{abstract}

Keywords: Fish nodavirus; Grouper; Nervous necrosis virus; Temperature effect

\section{Introduction}

Viral nervous necrosis (VNN) threatens hatchery production of larvae and juveniles of marine fish worldwide. In addition, the number of fish species affected by VNN disease has rapidly increased (Glazebrook et al., 1990; Yoshikoshi and Inoue 1990; Mori et al., 1991; Renault et al., 1991; Mori et al., 1992; Munday et al., 1992; Naikai et al., 1994; Nguyen et al., 1994; Fukuda

* Corresponding author. Fax: + 886-2-23687122.

E-mail address: shauchi@ccms.ntu.edu.tw (S.-C. Chi) et al., 1996; Chi et al., 1997; Grotomol et al., 1997; Le Breton et al., 1997). The causative agent of VNN disease, a non-enveloped bi-segmented single-strand positive-sense RNA virus with sizes from $25-30 \mathrm{~nm}$, has been classified in the family Nodaviridae because of its nucleic acid properties and protein profiles (Mori et al., 1992).

Mass mortality of hatchery-reared grouper larvae and juveniles has frequently occurred in Taiwan in recent years. In an earlier investigation, we purified a virus from moribund grouper (Epinephelus fuscogutatus and Epinephelus akaara) juveniles which was identified as a fish nodavirus, 
and subsequently named GNNV 9410 strain (Chi et al., 1997). In a related work, we not only established a new continuous cell line (GF-1) from the fin tissue of a grouper (Epinephelus coioides, Hamilton), but also demonstrated that it is highly susceptible to GNNV (Chi et al., 1999).

It is widely recognized that a high mortality rate attributed to VNN disease usually occurs in summer (Arimoto et al., 1994; Fukuda et al., 1996; Chi et al., 1997; Le Breton et al., 1997). It is also widely assumed that temperature plays an important role in inducing the outbreak of the VNN disease. In this study, we isolated GNNV from moribund grouper larvae in the GF-1 cell line, and examined the effect of temperature on GNNV infection in that cell line and in grouper larvae.

\section{Materials and methods}

\subsection{Virus isolation}

The virus used in this study was isolated from naturally VNN-infected grouper larvae reared in the Kaohsiung hatchery farm in August 1995, and was designated as GNNV 9508. The outbreak of VNN disease was observed in the larvae from 10-20 days old. Diseased larvae lost their appetites and swam in a whirling manner. All infected larvae died within 3 days. Polymerase chain reaction (PCR) using SJNNV capsid protein gene specific primer set (F2, R3) revealed that the moribund grouper larvae contained the conserved region of fish nodavirus gene. The primers for carrying out PCR amplification of the extracted nucleic acids were synthesized by DNAFax Company, and the primer sequences of these primers are based on those of Nishizawa et al. (1994).

GNNV 9508 was also isolated in the GF-1 cell line. The homogenate of moribund larvae was diluted in L15 medium. After centrifugation, the supernatant was filtered by a $0.22-\mu \mathrm{m}$ membrane, and then inoculated into GF-1 cells. After $1 \mathrm{~h}$ of adsorption at room temperature, the supernatant was discarded, and the cells were washed with phosphate buffer three times. Next, L15 medium with $2 \%$ fetal bovine serum (FBS) was added to the cells and incubated at $28^{\circ} \mathrm{C}$. Once the complete cytopathic effect (CPE) appeared, the cells and the culture supernatant were separated by centrifugation at $1000 \times g$ for $10 \mathrm{~min}$. The cell pellet was then prepared for electron microscope examination, and the supernatant was used to extract the viral nucleic acids for PCR examination. Titration of GNNV was performed in 96well plates seeded with GF-1 cells, and virus titer was calculated after incubation for 5 days.

\subsection{Electron microscopy}

Diseased larvae and GNNV-infected GF-1 cells were fixed in $2.5 \%$ glutaraldehyde in $0.1 \mathrm{M}$ phosphate buffer at $\mathrm{pH} 7.4$ and post-fixed in $1 \%$ osmium tetroxide. Ultrathin sections were stained with uranyl acetate-lead citrate and examined under a Hitachi H-600A electron microscope.

\subsection{PCR amplification of the coat protein gene of $G N N V$}

Viral RNA was extracted from the VNN-infected larvae by a method described in an earlier work (Chi et al., 1997). In addition, viral RNA was extracted from the supernatant of GNNV-infected GF-1 cell culture medium using a Rneasy mini kit (QIAGEN). The extracted RNAs were then reverse-transcribed by MMLV reverse transcriptase and then amplified by using primer sets (F2, R3) specific to SJNNV RNA2 gene according to our method described in Chi et al. (1997).

\subsection{Effect of temperature on GNNV infection in vitro}

GF-1 cells were grown to a monolayer in 25 $\mathrm{cm}^{2}$ flasks with L15-5\% FBS. The culture fluid was removed and duplicate flasks were inoculated with $1 \times 10^{2} \quad 50 \%$ tissue culture infective doses (TCID $_{50}$ ) of each virus in $1 \mathrm{ml} \mathrm{L15-2 \%} \mathrm{FBS.} \mathrm{The}$ negative control GF-1 cells were inoculated with PBS instead of GNNV. After $1 \mathrm{~h}$ of adsorption, the cells were washed three times with PBS, and 5 $\mathrm{ml}$ L15-2\% FBS were added to each flask. The flasks were then incubated at $20^{\circ} \mathrm{C}, 24^{\circ} \mathrm{C}, 28^{\circ} \mathrm{C}$, $32^{\circ} \mathrm{C}$ and $37^{\circ} \mathrm{C}$, respectively. After 5 days of 
observation, released virus (RV) in the supernatant of culture medium and cell associated virus (CAV) in the cell debris were titrated. Titration of $\mathrm{RV}$ and CAV were performed in 96-well plates seeded with GF-1 cells and cultured at $28^{\circ} \mathrm{C}$.

\subsection{Western immunoblot}

After 5 days of incubation, GNNV-infected cell pellets prepared by centrifugation at $1000 \times g$ for 10 min were analyzed in Western immunoblot by using anti-GNNV mouse antiserum produced in our laboratory. After 10\% sodium dodecyl sulfate-polyacrylamide electrophoresis (SDSPAGE), the proteins were blotted onto immobilon membranes (Gibco) according to the method described in Chi et al. (1991).

\subsection{Effect of temperature on GNNV infection in vivo}

A challenge test in grouper larvae with GNNV was performed at the end of October 1997 in southern Taiwan. Results obtained from the PCR test before the challenge experiment confirmed that the grouper eggs and hatched larvae were GNNV-free (data not shown). Four tanks of grouper larvae (3000 larvae in 501 of seawater in each tank) were divided into two groups, with one group maintained at constant $28^{\circ} \mathrm{C}$ using a heater, and the other group was maintained at ambient temperature, which was about $28^{\circ} \mathrm{C}$ at noon and about $24^{\circ} \mathrm{C}$ at night. In each test group, $100 \mathrm{ml}$ supernatant of GNNV-infected GF-1 cell medium with a titer of $10^{8} \mathrm{TCID}_{50} / 0.1 \mathrm{ml}$ was added to 10 1 of rearing water; while in each control tank only L15 medium was added. After $4 \mathrm{~h}$ of bath challenge, the water was gradually replaced by 501 of clean seawater. The accumulated death rate in each tank was approximately counted. Larvae samples (five larvae of each tank) were collected at different time intervals post challenge, washed three times by PBS, and tested by PCR using a primer set (F2, R3) specific to a conserved T4 target region of SJNNV coat protein gene.

\section{Results}

\subsection{Virus isolation}

CPE was observed in GF-1 cell line 3 days after inoculating with the filtrate of diseased grouper larvae. CPE developed initially as some areas of
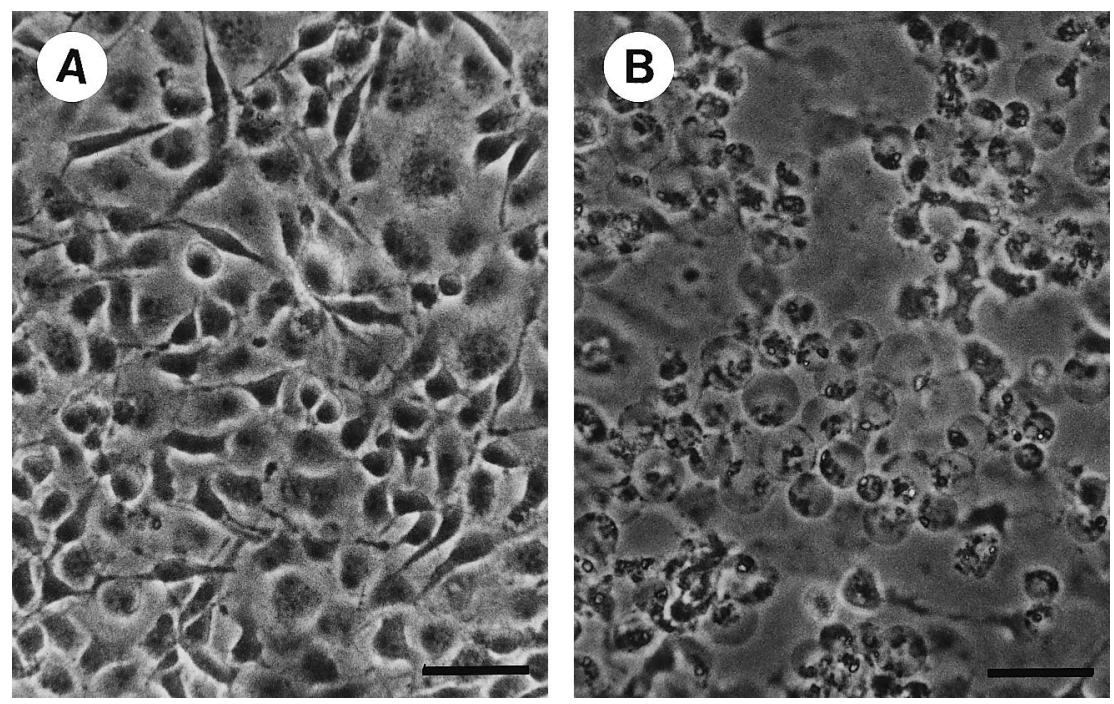

Fig. 1. Morphology of (A) non-infected GF-1 cells and (B) GNNV-infected GF-1 cells with apparent CPE (phase contrast). Bar $=50$ $\mu \mathrm{m}$. 

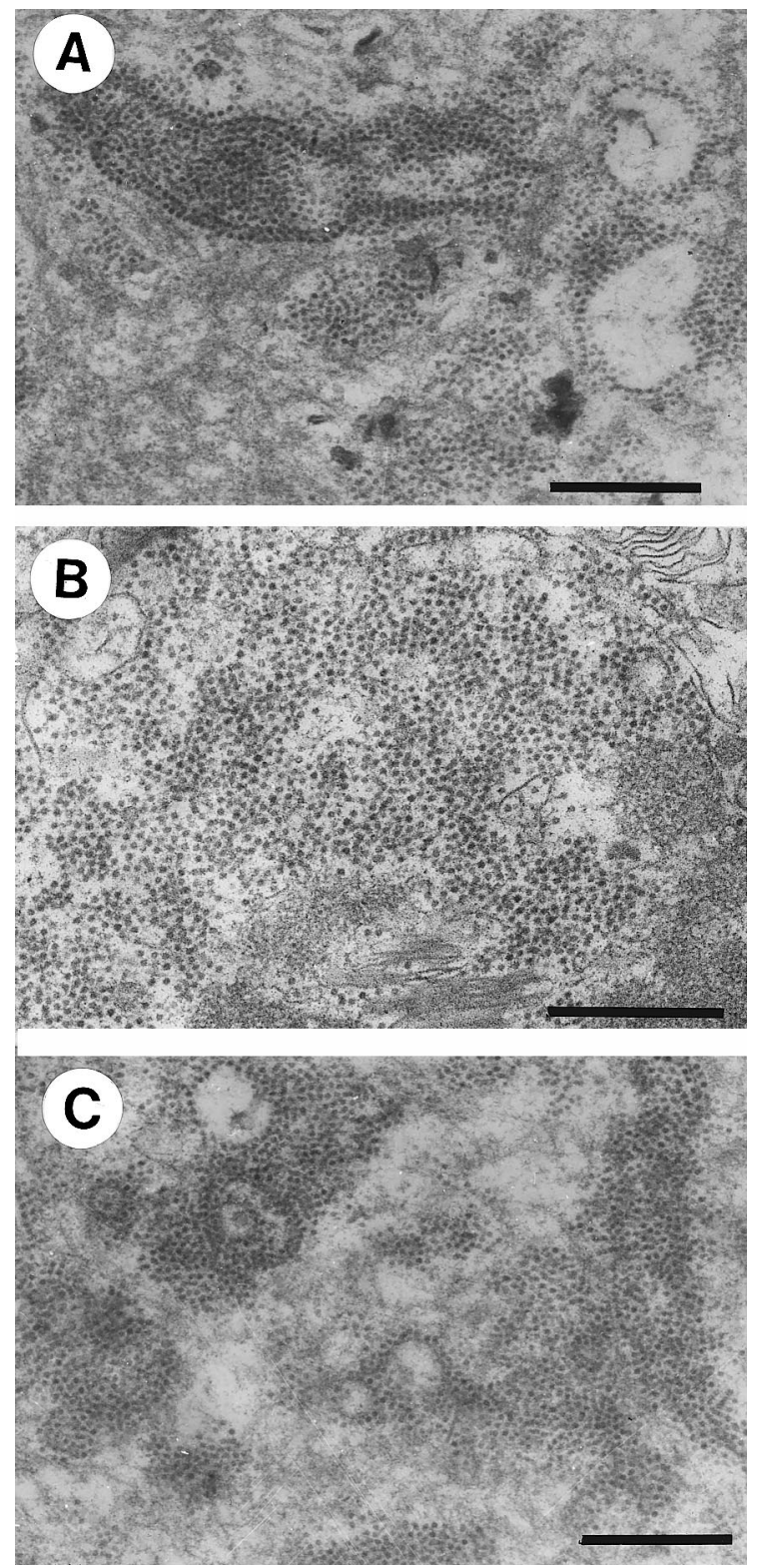

Fig. 2. Electron microscopy showing abundant non-enveloped, spherical viral particles in the cytoplasm of (A) naturally GNNV-infected grouper larvae brain cells, (B) GNNV-infected GF-1 cells and (C) GNNV-challenged grouper larvae brain cells. $\mathrm{Bar}=500 \mathrm{~nm}$.

rounded, granular, refractive cells and then spread to the complete cell sheet; finally, the cells degenerated and floated in the medium (Fig. 1). The same CPE was reproduced in three passages and the titer increased to $10^{7} \mathrm{TCID}_{50} / 0.1 \mathrm{ml}$.

\subsection{Electron microscopy}

Electron microscopy revealed that numerous non-enveloped, homogeneous, spherical to icosahedral particles with diameter of $20-25 \mathrm{~nm}$ were in the cytoplasm of brain cells of naturally infected grouper larvae, GNNV-infected GF-1 cells and brain cells of GNNV-challenged larvae (Fig. $2)$. This observation implied that the viral particles amplified in the GF-1 cells exhibit the same morphology as the viral particles in the naturally GNNV-infected fish and GNNV-challenged fish.

\subsection{PCR amplification of nucleic acids from in vivo and in vitro GNNV-infected cells}

Deproteinized nucleic acids extracted from naturally GNNV-infected grouper larvae, GNNV-infected GF-1 cells and GNNV-challenged grouper larvae were reverse transcribed and analyzed by PCR amplification using primers specific to SJNNV RNA2. The PCR products were approximately 430 bp (T4: F2, R3 primer set) (Nishizawa et al., 1994). Fig. 3 summarizes those results. The PCR products corresponding to T4 were amplified from the nucleic acids of naturally infected larvae, GNNV-infected GF-1 cells and GNNVchallenged larvae.

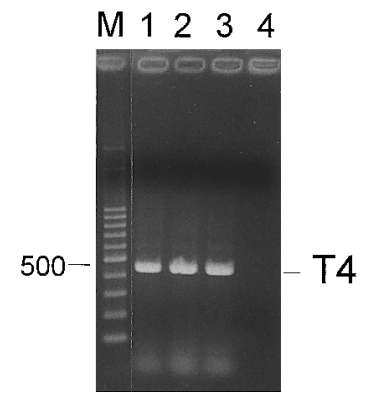

Fig. 3. Agarose gel electrophoresis of products in the PCR amplification using the $(\mathrm{F} 2, \mathrm{R} 3)$ primer set specific to the $\mathrm{T} 2$ target region (lanes $1-4$ ). The template cDNA was prepared from naturally GNNV-infected larvae (lane 1), GNNV-infected GF-1 cells (lane 2), and GNNV-challenged grouper larvae (lane 3). Lane 4 shows a template-free control reaction. M, DNA ladder marker (Promega). 
Table 1

Temperature effects on GNNV infection in GF-1 cells

\begin{tabular}{|c|c|c|c|c|}
\hline $\begin{array}{l}\text { Adsorption temperature } \\
\left({ }^{\circ} \mathrm{C}\right)\end{array}$ & $\begin{array}{l}\text { Incubation temperature } \\
\left({ }^{\circ} \mathrm{C}\right)\end{array}$ & CPE & $\begin{array}{l}\text { Titer of } \mathrm{RV}^{\mathrm{a}} \\
\left(\mathrm{TCID}_{50} / 0.1 \mathrm{ml}\right)\end{array}$ & $\begin{array}{l}\text { Titer of } \mathrm{CAV}^{\mathrm{b}} \\
\left(\mathrm{TCID}_{50} / 0.1 \mathrm{ml}\right)\end{array}$ \\
\hline 28 & 20 & - & $10^{1.0}$ & $10^{3.0}$ \\
\hline 28 & 24 & + & $10^{4.5}$ & $10^{5.5}$ \\
\hline 28 & 28 & + & $10^{6.0}$ & $10^{7.0}$ \\
\hline 28 & 32 & + & $10^{6.0}$ & $10^{7.0}$ \\
\hline 24 & 24 & + & $10^{4.0}$ & $10^{5.0}$ \\
\hline 28 & 28 & + & $10^{6.0}$ & $10^{7.0}$ \\
\hline 32 & 32 & + & $10^{6.3}$ & $10^{7.1}$ \\
\hline 37 & 37 & - & 0 & 0 \\
\hline
\end{tabular}

${ }^{a}$ Released virus.

${ }^{\mathrm{b}}$ Cell associated virus.

\subsection{Effect of temperature on GNNV infection in vitro}

Five temperatures were tested for the GNNV infection in GF-1 cells. Whether the adsorption temperature was the same as the incubation temperature or not, CPE was always observed in the GNNV-infected GF cells incubated at $24-32^{\circ} \mathrm{C}$ at 3 days post-infection (p.i.), but no CPE was found in GNNV-infected cells incubated at $20^{\circ} \mathrm{C}$ or $37^{\circ} \mathrm{C}$ even after 5 days p.i. (Table 1). Infectious GNNV could be detected in the cell pellet and in the supernatant of culture cells incubated at $20-$ $32^{\circ} \mathrm{C}$, but no virus was detected in the cells incubated at $37^{\circ} \mathrm{C}$ (Table 1). Non-infected GF-1 cells retained normal morphology even after 5 days of incubation at five separate temperatures.

Western immunoblot using anti-GNNV mouse antiserum revealed the presence of viral protein in GNNV-infected cells cultured at $20-32^{\circ} \mathrm{C}$, and those results indicated that viral mRNA could successfully translate into viral polypeptide within the host cells at $20-32^{\circ} \mathrm{C}$. Within the permissive temperatures, the amount of viral protein increased with an increasing cell culture temperature. Viral proteins were not detected either in the GNNV-infected cells cultured at $37^{\circ} \mathrm{C}$ or in the non-infected cells (Fig. 4).

The clarified tissue culture fluid of GNNV-infected cells after 5 days of incubation at different temperatures was used to detect GNNV nucleic acids by PCR amplification. T4 target region of primer set (F2, R3) could be amplified from GNNV-infected cells cultured at $20-32^{\circ} \mathrm{C}$, but not from the cells cultured at $37^{\circ} \mathrm{C}$ (Fig. 5).

\subsection{Effect of temperature on GNNV infection in vivo}

Table 2 shows the effect of temperature on GNNV in vivo. The larvae in the test tank cultured at a constant $28^{\circ} \mathrm{C}$ exhibited $80 \%$ death rate 1 day post challenge (p.c.) and the cumulative death rate increased to $100 \%$ at 50 h p.c., while a cumulative death rate of less than $5 \%$ was ob-

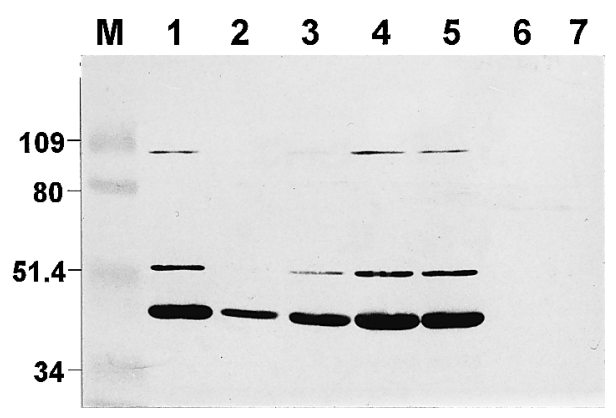

Fig. 4. Detection of GNNV protein in GNNV-infected GF-1 cells incubated at different temperatures in Western immunoblot by using anti-GNNV mouse anti-serum. M, BioRad prestained SDS-PAGE marker. Lane 1, purified GNNV. Lanes 2-6, GNNV-infected cells separately incubated at $20^{\circ} \mathrm{C}$, $24^{\circ} \mathrm{C}, 28^{\circ} \mathrm{C}, 32^{\circ} \mathrm{C}$ and $37^{\circ} \mathrm{C}$. Lane 7 , non-infected GF-1 cells. 


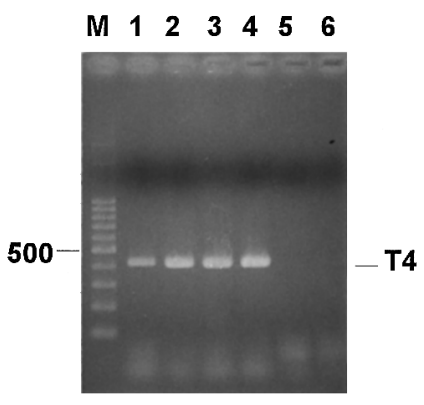

Fig. 5. Detection T4 target region using NNV specific primer set (F2, R3) in PCR amplification by adding cDNA templates derived from GNNV-infected GF-1 cells incubated at different temperatures (lane $1,20^{\circ} \mathrm{C}$; lane $2,24^{\circ} \mathrm{C}$; lane $3,28^{\circ} \mathrm{C}$; lane 4 , $32^{\circ} \mathrm{C}$; lane $5,37^{\circ} \mathrm{C}$ ). Lane 6 indicates a template-free control reaction. $\mathrm{M}$, DNA ladder maker (Promega).

served in the control larvae. The cumulative death rate of the larvae at ambient temperature $\left(28^{\circ} \mathrm{C}\right.$ at noon and $24^{\circ} \mathrm{C}$ at night) was about $10 \% 1$ day p.c. and increased to $60 \%$ at 50 h p.c. Only by 80 h p.c. did mortality increase to $100 \%$, compared to a death rate in the control group of only $10 \%$. PCR examinations were performed with challenged larvae after 10, 20, 30, 50, 80 and $270 \mathrm{~h}$ (controls) p.c. PCR products corresponding to the $\mathrm{T} 4$ region of $\mathrm{VNN}$ were amplified from the nucleic acid of GNNV-challenged larvae cultured at constant $28^{\circ} \mathrm{C}$ for $10 \mathrm{~h}$ p.c., but was detected in GNNV-challenged larvae cultured at ambient temperature for $20 \mathrm{~h}$ p.c. No PCR products were detected in the negative control larvae even at 270 h p.c.

\section{Discussion}

Results obtained from electron microscopy, PCR and the challenge test confirmed that the causative agent of the mass mortalities of grouper larvae was fish nervous necrosis virus which was designated GNNV 9508. The GF-1 cell line is a novel cell line, capable of replicating between 18 and $37^{\circ} \mathrm{C}$, and is highly susceptible to GNNV infection (Chi et al., 1999). In this study, we found that the appropriate temperature range for GNNV infection is $24-32^{\circ} \mathrm{C}$; within this temperature range, virus titer increased with an increase of the temperature (Table 1).

No CPE was observed in the GNNV-infected cells incubated at $20^{\circ} \mathrm{C}$ or $37^{\circ} \mathrm{C}$ regardless of whether or not the viral adsorption temperature was the same as incubation temperature (Table 1); therefore, the inhibition of $\mathrm{CPE}$ at $20^{\circ} \mathrm{C}$ and $37^{\circ} \mathrm{C}$ is not at the adsorption level. Although no CPE is observed at $20^{\circ} \mathrm{C}$, GNNV was still able to infect GF-1 cells and express its GNNV gene product, but the replication rate at $20^{\circ} \mathrm{C}$ is lower than that at $24-32^{\circ} \mathrm{C}$ (Fig. 4).

A nodavirus from juvenile sea bass (Dicentrarchus labrax L.) was isolated in the $\mathrm{SNN}-1$ cell line, derived from striped snakehead (Channa striatus), at $20^{\circ} \mathrm{C}$ (Frerichs et al., 1996). However, Le Breton et al. (1997) reported that, in vivo, mortalities of VNN-infected sea bass, Dicentrarchus labrax (L.), ceased when the water temperature decreased to $20^{\circ} \mathrm{C}$. Therefore, the temperature effect on VNN infection in vitro and in vivo displayed some variations among different isolates.

Table 2

The temperature effects on GNNV infection of GNNV-challenged grouper larvae

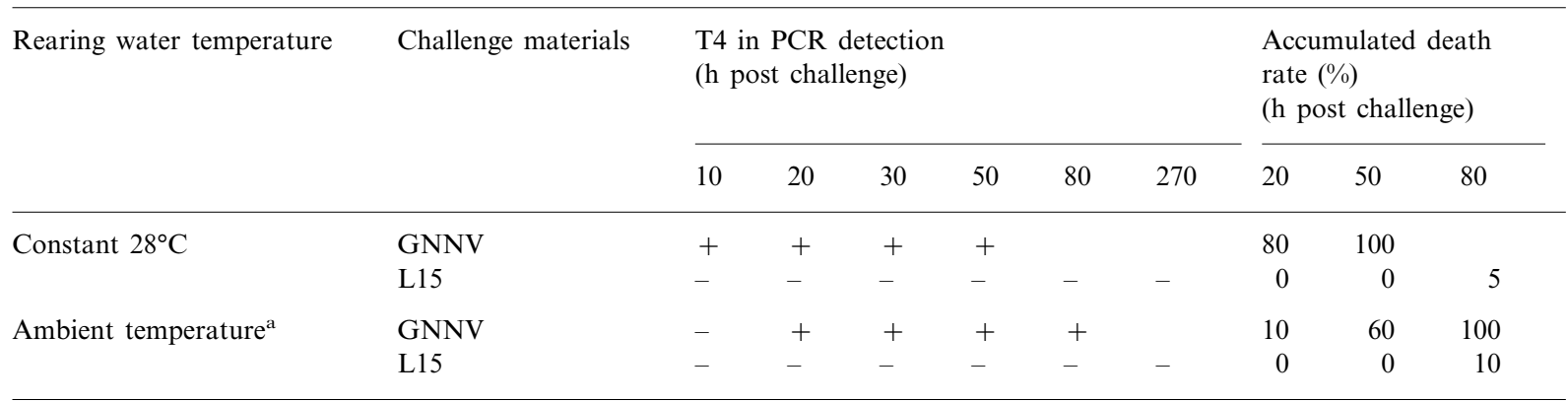

a Ambient temperature is about $28^{\circ} \mathrm{C}$ at noon and $24^{\circ} \mathrm{C}$ at night. 
As neither viral protein nor viral nucleic acids could be detected in the GNNV-infected GF-1 cells incubated at $37^{\circ} \mathrm{C}$ (Figs. 3 and 4), we can infer that GNNV does not infect mammals owing to the temperature factor. Until now, only one mammalian cell line, Simian $\operatorname{Cos} 1$, has been reported to be permissive to another fish nodavirus isolate DIEV (Dicentrarchus labrax encephalitis virus), but the virus titer was very low and no CPE was observed (Delsert et al., 1997).

Mass mortalities associated with VNN have been reported during summer in several species of grouper and sea bass, and water temperature during mass mortalities in these reports ranged from 25 to $28^{\circ} \mathrm{C}$; however, the mortality ceased when the temperature decreased to $23^{\circ} \mathrm{C}$ or lower (Mori et al., 1991; Fukuda et al., 1996; Le Breton et al., 1997). In Taiwan, VNN disease repeatedly occurred from April to September, and the peak of mortalities was recorded in summer (June to August) when the average temperature is around $30-32^{\circ} \mathrm{C}$; mortalities have gradually decreased since October. According to the results of in vitro temperature effect on VNN infection, we suggest that in winter VNN still can infect the fish, and replicate within the host cells as a state of persistent infection, and will not cause cell necrosis or mortality of fish. The preliminary results of in vivo temperature effect on GNNV infection also indicated that, within the permissive temperatures for viral infection, lower temperature will delay the outbreak of mass mortality (Table 2).

\section{Acknowledgements}

The authors would like to thank the National Science Council of the Republic of China for financially supporting this research under grant no. 88-2311-B-002-057.

\section{References}

Arimoto, M., Maruyama, K., Furusawa, I., 1994. Epizootiology of viral nervous necrosis (VNN) in striped jack. Fish Pathol. 29, 19-24.
Chi, S.C., Chen, S.N., Kou, G.H., 1991. Establishment, characterization and application of monoclonal antibodies against eel virus European (EVE). Fish Pathol. 26 (1), 1-7.

Chi, S.C., Lo, C.F., Kou, G.H., Chang, P.S., Peng, S.E., Chen, S.N., 1997. Mass mortalities associated with viral nervous necrosis (VNN) disease in two species of hatcheryreared grouper, Epinephelus fuscugutatus and Epinephelus akaara (Temminck \& Schelgel). J. Fish Dis. 20, 185-193.

Chi, S.C., Hu, W.W., Lo, B.J., 1999. Establishment and characterization of a continuous cell line (GF-1) derived from grouper, Epinephelus coioides (Hamilton): a cell line susceptible to grouper nervous necrosis virus (GNNV). J. Fish Dis. 22, 1-10.

Delsert, C., Morin, N., Comps, M., 1997. Fish nodavirus lytic cycle and semipermissive expression in mammalian and fish cell cultures. J. Virol. 71, 5673-5677.

Frerichs, G.N., Rodger, H.D., Peric, Z., 1996. Cell culture isolation of piscine neuropathy nodavirus from juvenile sea bass, Dicentrarchus labrax. J. Gen. Virol. 77, 2067-2071.

Fukuda, Y., Nguyen, H.D., Furuhashi, M., Nakai, T., 1996. Mass mortality of cultured sevenband grouper, Epinephelus septemfasciatus, associated with viral nervous necrosis. Fish Pathol. 31 (3), 165-170.

Glazebrook, J.S., Haesman, M.P., Beer, S.W., 1990. Picornalike viral particles associated with mass mortalities in larval baramundi, Lates calcarifer Bloch. J. Fish Dis. 13, 245249.

Grotomol, S., Totland, G.K., Kryvi, H., 1997. Detection of a nodavirus-like agent in heart tissue from reared Atlantic salmon Salmo salar suffering from cardiac myopathy syndrome (CMS). Dis. Aquat. Org. 29 (2), 79-84.

Le Breton, A., Grisez, L., Sweetman, J., Ollevier, F., 1997. Viral nervous necrosis (VNN) associated with mass mortalities in cage-reared sea bass, Dicentrarchus labrax L. J. Fish Dis. 20 (2), 145-151.

Mori, K., Nakai, T., Negahara, M., Muroga, K., Mckuchi, T., Kanno, T., 1991. A viral disease in hatchery-reared larvae and juveniles of redspotted grouper. Fish Pathol. 26, 209210.

Mori, K., Nakai, T., Muroga, K., Arimoto, M., Mushiakc, K., Furuswa, I., 1992. Properties of a new virus belong to Nodaviridae found in larval striped jack (Pseudocaranx dentex) with nervous necrosis. Virology 187, 378-381.

Munday, B.L., Langdon, J.S., Hyatt, A., Humphrey, J.D., 1992. Mass mortalities associated with a viral-induced vacuolating encephalopathy and retinopathy of larval and juvenile barramundi, Lates calcarifer Bloch. Aquaculture 103, 197-211.

Naikai, T., Nguyen, H.D., Nishizawa, T., Muroga, K., Arimoto, M., Ootsuki, K., 1994. Occurrence of viral nervous necrosis in kelp grouper and tiger puffer. Fish Pathol. 29, $211-212$.

Nguyen, H.D., Mekuchi, T., Imura, K., Naikai, T., Nishizawa, T., Muroga, K., 1994. Occurrence of viral nervous necrosis (VNN) in hatchery-reared juvenile Japanese flounder Paralichthys olivaceus. Fish Sci. 60, $551-554$. 
Nishizawa, T., Mori, K., Nakai, T., Furusawa, I., Muroga, K., 1994. Polymerase chain reaction amplification of RNA of striped jack nervous necrosis virus (SJNNV). Dis. Aquat. Org. 18, 103-107.

Renault, T., Haffner, P., Baudin, L.F., Breuil, G., Bonami, J.R., 1991. Mass mortalities in hatchery-reared sea bass Lates calcarifer larvae associated with the presence in the brain and retina of virus-like particles. Bull. Eur. Assoc. Fish Pathol. 11, 68-73.

Yoshikoshi, K., Inoue, K., 1990. Viral nervous necrosis in hatchery-reared larvae and juveniles of Japanese parrotfish, Oplegnathus fasciatus (Temminck \& Schlegel). J. Fish Dis. 13, 69-77. 